\title{
Physical activity, food intake, and body weight regulation: insights from doubly labeled water studies
}

Citation for published version (APA):

Westerterp, K. R. (2010). Physical activity, food intake, and body weight regulation: insights from doubly labeled water studies. Nutrition Reviews, 68(3), 148-54. https://doi.org/10.1111/j.1753-4887.2010.00270.x

Document status and date:

Published: 01/01/2010

DOI:

10.1111/j.1753-4887.2010.00270.x

Document Version:

Publisher's PDF, also known as Version of record

Document license:

Taverne

\section{Please check the document version of this publication:}

- A submitted manuscript is the version of the article upon submission and before peer-review. There can be important differences between the submitted version and the official published version of record.

People interested in the research are advised to contact the author for the final version of the publication, or visit the DOI to the publisher's website.

- The final author version and the galley proof are versions of the publication after peer review.

- The final published version features the final layout of the paper including the volume, issue and page numbers.

Link to publication

\footnotetext{
General rights rights.

- You may freely distribute the URL identifying the publication in the public portal. please follow below link for the End User Agreement:

www.umlib.nl/taverne-license

Take down policy

If you believe that this document breaches copyright please contact us at:

repository@maastrichtuniversity.nl

providing details and we will investigate your claim.
}

Copyright and moral rights for the publications made accessible in the public portal are retained by the authors and/or other copyright owners and it is a condition of accessing publications that users recognise and abide by the legal requirements associated with these

- Users may download and print one copy of any publication from the public portal for the purpose of private study or research.

- You may not further distribute the material or use it for any profit-making activity or commercial gain

If the publication is distributed under the terms of Article $25 \mathrm{fa}$ of the Dutch Copyright Act, indicated by the "Taverne" license above, 


\section{Physical activity, food intake, and body weight regulation: insights from doubly labeled water studies}

Klaas R Westerterp

Body weight and energy balance can be maintained by adapting energy intake to changes in energy expenditure and vice versa, whereas short-term changes in energy expenditure are mainly caused by physical activity. This review investigates whether physical activity is affected by over- and undereating, whether intake is affected by an increase or a decrease in physical activity, and whether being overweight affects physical activity. The available evidence is based largely on studies that quantified physical activity with doubly labeled water. Overeating does not affect physical activity, while undereating decreases habitual or voluntary physical activity. Thus, it is easier to gain weight than to lose weight. An exercise-induced increase in energy requirement is typically compensated by increased energy intake, while a change to a more sedentary routine does not induce an equivalent reduction of intake and generally results in weight gain. Overweight and obese subjects tend to have similar activity energy expenditures to lean people despite being more sedentary. There are two ways in which the general population trend towards increasing body weight can be reversed: reduce intake or increase physical activity. The results of the present literature review indicate that eating less is the most effective method for preventing weight gain, despite the potential for a negative effect on physical activity when a negative energy balance is reached.

(c) 2010 International Life Sciences Institute

\section{INTRODUCTION}

Food intake is a function of energy requirement as determined by body size and physical activity. Adult humans maintain a balance between their energy intake and energy expenditure levels, as demonstrated by the constancy of body weight and body composition. This can be achieved by controlling either energy intake or expenditure. Humans, however, do not balance energy intake and energy expenditure on a daily basis, as smaller animals do. They can afford to rely on their body's reserves while smaller species show signs of energy shortage sooner in the form of lowered body temperature and reduced physical activity. Smaller species have a higher level of energy expenditure per kg body mass as well as a relatively smaller body energy reserve. Thus, a mouse cannot survive 3 days without food, while a normal adult human being can survive more than 30 days.

Of course, humans are able to maintain a perfect energy balance over the long term, as shown by a constant body weight in adult life. An average individual has a daily energy turnover of $10-15 \mathrm{MJ}$ or $3650-5475 \mathrm{MJ} / \mathrm{y}$. Even a weight change of $1 \mathrm{~kg}$, equivalent to $30 \mathrm{MJ}$, denotes a discrepancy between intake and expenditure of only 0.6$0.8 \%$ on an annual basis. Energy intake strongly correlates with energy expenditure on a weekly basis. Daily discrepancies between intake and expenditure are especially large when days with high energy expenditure are alternated with quieter intervals. Military cadets did not show an increase in energy intake on days with higher energy expenditure when they joined a drill competition; the

Affiliation: KR Westerterp is with the Department of Human Biology, Maastricht University, Maastricht, the Netherlands.

Correspondence: KR Westerterp, Department of Human Biology, Maastricht University, PO Box 616, 6200 MD Maastricht, the Netherlands.

E-mail: k.westerterp@hb.unimaas.nl, Phone: +31-43-3881628, Fax: +31-43-3670976.

Key words: doubly labeled water, energy balance, exercise training, obesity, overeating, undereating

doi:10.1111/j.1753-4887.2010.00270.x 
corresponding increase in energy intake came about 2 days afterwards. ${ }^{1}$

Humans can change their energy intake by a factor of at least three when adapting it to the expenditure of energy. The opposite possibility of humans adapting energy expenditure to energy intake is often questioned. It has even been stated by some that the control of energy expenditure is contrary to what the body weight would require in such cases as hyperactivity in anorexics and hypoactivity in obesity. Reviewed here is the available evidence for energy expenditure adapting to energy intake and vice versa. Adaptations in both directions have been shown in studies in which energy intake is either decreased or increased through overeating or undereating, respectively, and studies in which energy expenditure is decreased or increased, through changes in physical activity. The review is divided into the following sections: overeating and physical activity; undereating and physical activity; exercise training and food intake; reduced physical activity and food intake; and physical activity and body weight.

\section{OVEREATING AND PHYSICAL ACTIVITY}

Several studies have estimated the effect of overeating on physical activity. This review focused on six studies in which physical activity was measured under free-living conditions, i.e., with doubly labeled water. In these studies, subjects were overfed with $20-100 \%$ of weight maintenance intake for 14-65 days. The studies included a total of 54 subjects ( 19 women and 35 men) with a mean age of 30 years (range 19-58 y). The physical activity level (PAL), calculated by expressing total energy expenditure as a multiple of resting energy expenditure, at baseline was 1.75 (Table 1 ), ${ }^{2-7}$ similar to the mean PAL values reported for Europe and North America. ${ }^{8}$ The effect of overfeeding on PAL was non-significant in four studies. One study showed an overfeeding-induced increase in PAL. ${ }^{5}$ However, baseline PAL was calculated based on energy intake for weight maintenance and PAL derived from accelerometers, as measured at baseline $(2,905 \pm$ 514 units/d) and during overfeeding (2,963 \pm 537 units/d), was not changed. Finally, in the study that found an overfeeding-induced decrease in PAL, subjects were massively overfed, with intake doubled for 9 weeks, resulting in a body weight gain of $17 \pm 4 \mathrm{~kg}$. ${ }^{4}$ The weight increases reported in the other studies range from $1.5 \mathrm{~kg}$ over 2 weeks to $7.6 \mathrm{~kg}$ over 6 weeks or from $0.7 \mathrm{~kg} / \mathrm{wk}$ to $1.3 \mathrm{~kg} / \mathrm{wk}$. In conclusion, there does not seem to be an effect of overfeeding on physical activity when overfeeding is lower than twice the maintenance requirements, as observed in studies lasting up to 9 weeks.

\section{UNDEREATING AND PHYSICAL ACTIVITY}

Energy restriction results in a reduction of energy expenditure by the following means: a reduction of maintenance metabolism or basal metabolic rate, diet-induced energy expenditure, and activity-induced energy expenditure. In the classical Minnesota experiment, young men with a maintenance requirement of $14.6 \mathrm{MJ} / \mathrm{d}$ were restricted to $6.6 \mathrm{MJ} / \mathrm{d}$ for 24 weeks. ${ }^{9}$ They reached energy balance at the end of the experiment, with $58 \%$ of the total energy saving being ascribed to a reduction of activityinduced energy expenditure; of this total energy saving, $40 \%$ was due to reduced body weight and $60 \%$ was due to reduced physical activity.

A recent randomized controlled trial on the effects of energy restriction showed similar results. Here, intake in overweight subjects was restricted to $75 \%$ of the baseline energy requirement for 6 months. Activity-related energy expenditure, as evaluated at 3 months and 6 months by adjusting doubly labeled water to assess total energy expenditure for metabolic body size, decreased significantly. ${ }^{10}$ This indicates a decrease in habitual or voluntary physical activity.

Studies on the effectiveness of diet-plus-exercise interventions versus diet-only interventions for weight loss show it is difficult to overcome a diet-induced reduction of physical activity with exercise training. A metaanalysis of a total of 18 randomized controlled trials on weight loss conducted for a minimum of 6 months showed an overall difference between the two groups of only $0.25 \mathrm{~kg}(95 \% \mathrm{CI}-0.36-0.14) .{ }^{11}$ At a negative energy

Table 1 Overfeeding studies in which total energy expenditure was measured with doubly labeled water.

\begin{tabular}{lllcc}
\hline Reference & Subjects & Overfeeding & $\mathrm{PAL}_{\text {baseline }}{ }^{\dagger}$ & $\mathrm{PAL}_{\text {overfeeding }}$ \\
\hline Roberts et al. (1990) & 7 males, normal weight & 3 weeks $+4.2 \mathrm{MJ}$ & $1.85 \pm 0.01$ & $1.89 \pm 0.04^{\text {ns }}$ \\
Diaz et al. $(1992)^{3}$ & 9 males, normal/overweight & 6 weeks, 150\% baseline & $1.8 \pm 0.2$ & $1.8 \pm 0.3^{\text {ns }}$ \\
Pasquet (1992) & 9 males, normal weight & 9 weeks, 200\% baseline & $1.87 \pm 0.12$ & $1.45 \pm 0.09^{*}$ \\
Levine et al. $(1999)^{5}$ & 4 females, 12 males, normal weight & 8 weeks $+4.2 \mathrm{MJ} / \mathrm{d}$ & $1.67 \pm 0.21^{\ddagger}$ & $1.90 \pm 0.28^{*}$ \\
Joosen et al. $(2005)^{6}$ & 7 females, normal weight & 2 weeks, 150\% baseline & $1.78 \pm 0.19$ & $1.77 \pm 0.21^{\text {ns }}$ \\
Siervo et al. $(2008)^{7}$ & 6 males, normal weight & 9 weeks, 120-160\% baseline & 1.60 & $1.65^{\text {ns }}$ \\
\hline
\end{tabular}

* Significantly different from baseline $(P<0.001)$.

${ }^{\dagger}$ Physical activity level, doubly labeled water-assessed energy expenditure as a multiple of resting energy expenditure.

${ }^{\ddagger}$ Energy intake as a multiple of resting energy expenditure. 
balance, the additional exercise is compensated by a reduction of non-training activity, resulting in a comparable decrease of total energy expenditure in the dietplus-exercise and the diet-only groups. ${ }^{12}$

\section{EXERCISE TRAINING AND FOOD INTAKE}

There are a limited number of studies that found an increase in energy expenditure, as measured with doubly labeled water, through exercise training while subjects had ad libitum access to food (Table 2). ${ }^{13-16}$ These studies included a total of 40 subjects: 10 boys aged $10-11$ years and 19 women and 11 men with a mean age of 30 years (range 23-41 y). The PAL at baseline was, at 1.71, close to the general population average for adults. ${ }^{8}$ Exerciseinduced increases in daily energy expenditure are moderate. The highest increase, as observed in the jogging intervention of Bingham et al., ${ }^{13}$ was $2.8 \mathrm{MJ} /$ day or $27 \%$ of the baseline value under sedentary conditions. With overfeeding interventions (Table 1), energy intake was increased to twice the value of intake for weight maintenance with a minimum of $4.2 \mathrm{MJ} /$ day. Despite the relatively smaller experimentally induced change in energy expenditure compared with energy intake, there must be a stimulatory effect on energy intake. Only the study with the smallest exercise-induced change in energy expenditure resulted in a negative energy balance, as reflected in significant weight loss. ${ }^{16}$ In the other studies, the maintenance of body weight indicated that the increase in energy expenditure was compensated by increased food intake. Even in the study that documented exerciseinduced weight loss, the weight loss was only about $50 \%$ of what could be expected without any intake compensation. In conclusion, an exercise-induced increase in energy expenditure induces increased energy intake, thus compensating for the additional requirement, especially at higher exercise loads.

\section{REDUCED PHYSICAL ACTIVITY AND FOOD INTAKE}

Doubly labeled water studies show that physical activityinduced energy expenditure decreases, on average, by more than $50 \%$ between the ages of 20 and 30 years and over the age of 65 years. ${ }^{17}$ Exercise training does not seem to prevent the age-associated decline in physical activity because it is compensated by a decrease in non-training physical activity. ${ }^{17}$ Thus, a physically active lifestyle inevitably results in a proportionally larger decrease of daily energy expenditure at later ages than a sedentary lifestyle. In a laboratory study, Stubbs et al. showed that reducing the PAL from 1.8 to 1.4 over 7 days markedly affected energy balance. A change to a sedentary routine did not induce a compensatory reduction of energy intake and most of the excess energy was stored as fat. ${ }^{18}$ Similarly, weight gain was observed in runners because of reductions in weekly exercise, and it was not reversed by resuming prior activity; this shows that intake follows an increase more than a decrease in activity-induced changes in daily energy expenditure. ${ }^{19}$ A recently reported study observed young adults over an average time interval of more than 10 years. ${ }^{20}$ Physical activity was measured over 2-week periods with doubly labeled water and doubly labeled water-validated triaxial accelerometers, and body fat gain was measured with isotope dilution. There was a significant association between the change in physical activity and the change in body fat, whereby a high initial activity level was predictive for greater fat gain. In conclusion, the change from a physically active to a more sedentary routine does not induce an equivalent reduction of energy intake and generally results in weight gain.

\section{PHYSICAL ACTIVITY AND BODY WEIGHT}

Energy expenditure is a function of body weight and physical activity. Since the application of the doubly labeled water technique for measuring total energy expenditure in free-living humans, we know that energy expenditure increases with body weight. Before, data on energy expenditure was derived from reported intake, resulting in the opposite conclusion. Figure 1 shows a typical example of reported intake (A) and measured expenditure (B) in the same subjects, with a body mass range from 51 to $103 \mathrm{~kg}$ for women and $59-141 \mathrm{~kg}$ for men. ${ }^{21-23}$ Reported intake is independent of weight in women, while in men reported intake is significantly lower in heavier subjects $(P<0.05)$. In both genders,

Table 2 Exercise training and body weight in studies measuring total energy expenditure with doubly labeled water.

\begin{tabular}{|c|c|c|c|c|}
\hline Reference & Subjects & Training mode & $\begin{array}{l}\Delta \text { Expenditure } \\
(\mathrm{MJ} / \mathrm{d})\end{array}$ & $\begin{array}{l}\Delta \text { Body } \\
\text { weight }(\mathrm{kg})\end{array}$ \\
\hline Bingham et al. (1989) & 2 females, 3 males, normal weight & Jogging for 9 weeks & $+2.8^{*}$ & $-0.9^{\text {ns }}$ \\
\hline Blaak et al. $(1992)^{14}$ & 10 boys, obese & Cycling for 4 weeks & $+1.3^{*}$ & $+0.5^{\mathrm{ns}}$ \\
\hline & 5 females, 8 males, normal weight & Jogging for 40 weeks & $+2.3^{* * *}$ & $-0.9^{\text {ns }}$ \\
\hline Westerterp et al. (1992) ${ }^{16}$ & 12 males, normal weight & Weight training for 12 weeks & $+0.8^{* *}$ & $-1.1^{*}$ \\
\hline
\end{tabular}


A

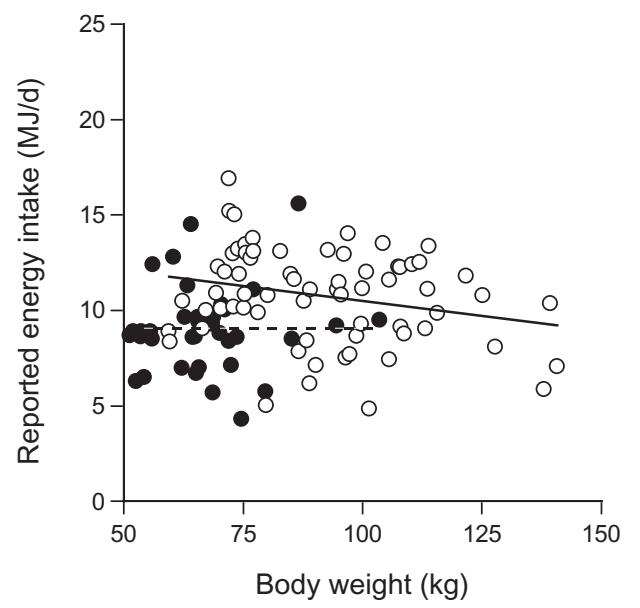

B

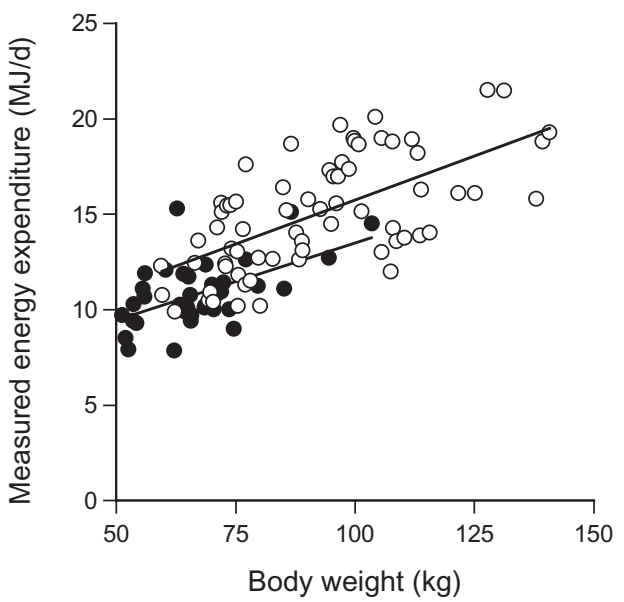

Figure 1 Reported energy intake as measured with a 7-day food record (A) and energy expenditure as measured simultaneously with doubly labeled water (B). Both measurements were made in the same subjects and plotted as a function of body weight for women (closed dots) and men (open dots), with linear regression lines denoting a significant relationship.

Data from Meijer et al. (1992), ${ }^{21}$ Westerterp et al. (1996), ${ }^{22}$ and Goris et al. (2000). ${ }^{23}$

measured expenditure is significantly higher than reported intake $(P<0.001)$ and is significantly higher in heavier subjects $(P<0.001)$. Heavier subjects tend to show more under-reporting of food intake than lean subjects. ${ }^{24}$ When reported intake is expressed as a multiple of the estimated basal metabolic rate, this food intakederived measure of physical activity is significantly lower in subjects with a higher body mass index. ${ }^{25}$ Reported intake as a multiple of the basal metabolic rate is often lower than the theoretical minimum of one, especially in overweight and obese subjects.

The first compilation of doubly labeled waterderived energy expenditure measurements showed no significant decrease in physical activity level, total energy expenditure as a multiple of the basal metabolic rate, or total energy expenditure minus the basal metabolic rate in most obese women and men. ${ }^{26} \mathrm{~A}$ study of adolescents attending the same school showed the higher energy expenditure observed in obese subjects is mainly due to a higher basal or maintenance metabolism (Figure 2). ${ }^{27}$ Activity-induced energy expenditure was similar for obese and gender-matched control subjects.

The fact that activity-induced energy expenditure is similar and not proportionally higher in subjects with a higher body weight has consequences for body movement. Indeed, body movement, as measured simultaneously with body-mounted accelerometers, was lower in obese subjects than in normal-weight subjects.

\section{IMPLICATIONS OF CURRENT FINDINGS}

The studies evaluated in this literature review indicate an increase in energy intake does not result in an increase in energy expenditure through more body movement. However, undereating seems to result in decreased habitual or voluntary physical activity and a diet-induced reduction of physical activity is difficult to overcome with exercise training. Under ad libitum food conditions, an exercise-induced increase in energy expenditure induces increased energy intake that compensates for the additional requirement, especially at higher exercise loads. The opposite, i.e., the change from a physically active to a

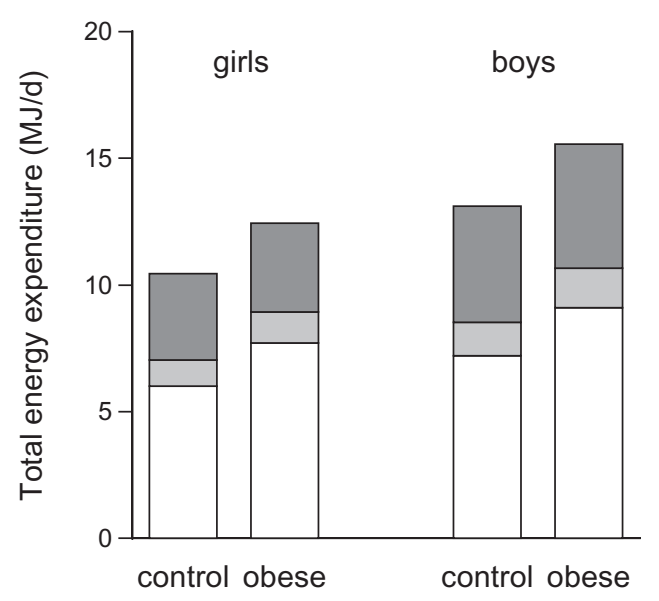

Figure 2 The three components of daily energy expenditure, basal metabolic rate (BMR), diet-induced energy expenditure (DEE), and activity-induced energy expenditure (AEE), as observed in control and obese adolescents from the same school. BMR and DEE are higher in obese than gender-matched control subjects $(P<0.001)$, while AEE is similar.

Data from Ekelund et al. (2002). ${ }^{27}$ 
more sedentary routine, does not induce an equivalent reduction of energy intake and generally results in weight gain. The higher energy expenditure in obese subjects is mainly due to a higher basal or maintenance metabolism while activity-induced energy expenditure is similar and not proportionally higher in subjects with a higher body weight. Thus, obese subjects eat more to maintain a higher body weight while moving less.

Unfortunately, under the current conditions of an ample food supply for the majority of the population, there is no increase in physical activity to offset a positive energy balance when overeating. The current obesity epidemic was originally explained by inactivity, based on a downward trend of reported intake, increasing use of cars for personal transportation, and time spent watching television. ${ }^{28}$ Now we know from doubly labeled water studies that subjects might be reporting energy intake according to their perceptions of expected intake instead of their actual intake and campaigns aimed at reducing fat intake might not be as successful as concluded from the results of national food consumption measurements. ${ }^{24}$ Physical inactivity cannot be the major or sole cause for the increasing prevalence of obesity given that review studies do not show a reduction in the levels of physical activity over the years and food intake is difficult to measure in free-living conditions. ${ }^{29}$ Physical activity energy expenditure, as measured with doubly labeled water, has not declined since the start of the obesity epidemic in the 1980 s. $^{8}$ A substantial increase in energy intake has driven the increase in body weight over the past decades. ${ }^{30}$

Theoretically, there are two options for reversing the general population trend towards increasing body weight: reducing intake or increasing physical activity. Preventing overeating by eating less is likely to be the most effective strategy, despite the potential for a negative effect on physical activity when a negative energy balance is reached. There is evidence that physical activity is of importance for weight maintenance, especially for the prevention of weight regains after weight loss. Schoeller et al. assessed physical activity energy expenditure in weight-reduced women and found that lower activity levels were associated with greater weight gains at followup. ${ }^{31}$ Weinsier et al. compared total free-living activity energy expenditure and physical activity levels in women who were successful and unsuccessful at maintaining a normal body weight. Two groups were identified on the basis of extreme weight changes: weight maintainers, who had a weight gain of $\leq 2 \mathrm{~kg} / \mathrm{y}$, and weight gainers, who had a weight gain of $\geq 6 \mathrm{~kg} / \mathrm{y} .{ }^{32}$ Gainers had lower activity energy expenditures, lower physical activity levels, and less muscle strength. A lower activity energy expenditure in the gainers explained $\sim 77 \%$ of their greater weight gain after 1 year.
The adaptation of food intake to an exercise-induced increase in energy requirement is not unlimited. At physical activity levels higher than approximately 2.5 , subjects have problems maintaining energy balance. ${ }^{33}$ Five studies performed on soldiers during field training, which collectively included 66 subjects with a mean PAL value of $2.40 \pm 0.46$, all reported a negative energy balance over the observation interval..$^{34-38}$ The body weight loss ranged from 0.4 to $2.3 \mathrm{~kg} / \mathrm{wk}$. Examples of energy balance being maintained at PAL values higher than 2.5 are available in studies of endurance athletes like runners, cross-country skiers, and professional cyclists. ${ }^{39-42}$ The differences between these studies and those with soldiers is probably twofold. First, professional endurance athletes comprise a segment of the population that has trained over many years to reach a high level of performance. Second, endurance athletes manage to maintain energy balance at a high level of energy turnover by supplementing their diets with energy-dense, carbohydrate-rich liquid formulae. ${ }^{43}$

The weight gain observed as a consequence of a change to a more sedentary routine was explained by the absence of an equivalent reduction of energy intake. Additionally, a more sedentary lifestyle might give more opportunities to eat in our obesogenic environment. Increased television viewing in children has been found to be associated with elevated body fatness but not with lower total energy expenditure ${ }^{44}$; the relationship between television viewing and fatness was explained by increased food intake during viewing.

While activity-induced energy expenditure is similar in subjects with a normal weight and those with a higher body weight, an overweight condition is limiting for high-intensity physical activity and physical performance. Jogging, for example, is not an ideal form of exercise for overweight subjects. In a prior study on the effect of an increase in physical activity on energy balance and body composition, our group studied subjects who were not participating in any sport before the start of the study and then prepared to run a half-marathon competition after 44 weeks of training. ${ }^{14}$ Subjects were recruited through an advertisement in the local media. Of 370 respondents, 16 women and 16 men, aged 28-41 years with BMIs between 19.4 and $26.4 \mathrm{~kg} / \mathrm{m}^{2}$, were selected. During the study, nine subjects withdrew, and all of them dropped out within 20 weeks of starting training. Reasons given for withdrawal were "not enough time to join the training" $(n=3)$, injuries $(n=5)$, and not able to keep up with the training $(n=1)$. The BMI of the dropouts was $23.4-26.4 \mathrm{~kg} / \mathrm{m}^{2}$, which was higher than the group mean of $22.9 \mathrm{~kg} / \mathrm{m}^{2}$. Although manifestly obese subjects were excluded by the selection criteria, most of the subjects with a BMI above 24 experienced difficulties with the training that led to their withdrawal. ${ }^{45}$ Similarly, in a study of voluntary recruits for military service, an 
overweight condition was the most important factor limiting high-level training. ${ }^{46}$

\section{CONCLUSION}

The results of the present literature review indicate an increase in physical activity results in an increase in food intake to maintain energy balance; however, an increase in energy intake does not result in an increase in energy expenditure through more body movement. People who are overweight exhibit activity-associated energy expenditure that is similar to lean people, but they eat more in order to cover the higher energy requirement for maintaining a larger body. The indicated method for energy balance maintenance is the prevention of overeating and the most successful method for weight loss is eating less.

\section{Acknowledgments}

Declaration of interest. The author has no relevant interests to declare.

\section{REFERENCES}

1. Edholm OG, Fletcher JG, Widdowson EM, McCance RA. The energy expenditure and food intake of individual men. $\mathrm{Br} \mathrm{J}$ Nutr. 1955;9:286-300.

2. Roberts SB, Young VR, Fuss $P$, et al. Energy expenditure and subsequent nutrient intakes in overfed young men. Am J Physiol. 1990;259:R461-R469.

3. Diaz EO, Prentice AM, Goldberg GR, Murgatroyd PR, Coward WA. Metabolic response to experimental overfeeding in lean and overweight healthy volunteers. Am J Clin Nutr. 1992:56:641-655.

4. Pasquet $P$, Brigant $L$, Froment $A$, et al. Massive overfeeding and energy balance in men: the Guru Walla model. Am J Clin Nutr. 1992;56:483-490.

5. Levine JA, Eberhardt NL, Jensen MD. Role of nonexercise activity thermogenesis in resistance to fat gain in humans. Science. 1999;283:212-214.

6. Joosen AMCP, Bakker AHF, Westerterp KR. Metabolic efficiency and energy expenditure during short-term overfeeding. Physiol Behav. 2005;85:593-597.

7. Siervo $M$, Frühbeck $G$, Dixon $A$, et al. Efficiency of autoregulatory homeostatic responses to imposed caloric excess in lean men. Am J Physiol Endocrinol Metab. 2008;294:E416E424.

8. Westerterp KR, Speakman JR. Physical activity energy expenditure has not declined since the 1980s and matches energy expenditures of wild mammals. Int J Obes. 2008;32:12561263.

9. Taylor HL, Keys A. Adaptation to caloric restriction. Science. 1950;112:215-218.

10. Redman LM, Heilbronn LK, Martin CK, et al. Metabolic and behavioral compensations in response to caloric retriction: implications for the maintenance of weight loss. PLOS ONE. 2009;4:e4377.

11. Wu T, Gao X, Chen M, van Dam RM. Long-term effectiveness of diet-plus-exercise interventions vs. diet-only interventions for weight loss: a meta-analysis. Obes Rev. 2009;10:313-323.
12. Kempen KPG, Saris WHM, Westerterp KR. Energy balance during 8 weeks energy-restrictive diet with and without exercise in obese females. Am J Clin Nutr. 1995;62:722-729.

13. Bingham SA, Goldberg GR, Coward WA, Prentice AM, Cummings $\mathrm{JH}$. The effect of exercise and improved physical fitness on basal metabolic rate. Br J Nutr. 1989;61:155173.

14. Blaak EE, Westerterp KR, Bar-Or O, Wouters LJ, Saris WH. Total energy expenditure and spontaneous activity in relation to training in obese boys. Am J Clin Nutr. 1992;55:777-782.

15. Westerterp KR, Meijer GA, Janssen EM, Saris WH, Ten Hoor F. Long-term effect of physical activity on energy balance and body composition. Br J Nutr. 1992;68:21-30.

16. Van Etten LM, Westerterp KR, Verstappen FT, Boon BJ, Saris WH. Effect of an 18-wk weight-training program on energy expenditure and physical activity. J Appl Physiol. 1997;82:298-304.

17. Westerterp KR, Plasqui G. Physical activity and human energy expenditure. Curr Opin Clin Nutr Metab Care. 2004;7:607613.

18. Stubbs RJ, Hughes DA, Johnstone AM, Horgan GW, King N. A decrease in physical activity affects appetite, energy, and nutrient balance in lean men feeding ad libitum. Am J Clin Nutr. 2004;79:62-69.

19. Williams PT. Asymmetric weight gain and loss from increasing and decreasing exercise. Med Sci Sports Exerc. 2008;40:296-302.

20. Westerterp KR, Plasqui G. Physically active lifestyle does not decrease the risk of fattening. PLoS ONE. 2009;4:e4745.

21. Meijer GAL, Westerterp KR, Van Hulsel AMP, Ten Hoor F. Physical activity and energy expenditure in lean and obese adult human subjects. Eur J Appl Physiol. 1992;65:525528.

22. Westerterp KR, Verboeket-van de Venne WPHG, Bouten CVC, De Graaf C, Van het Hof KH, Weststrate JA. Energy expenditure and physical activity in subjects consuming full- or reduced-fat diets. Br J Nutr. 1996;76:785-795.

23. Goris AHC, Westerterp-Plantenga MS, Westerterp KR. Undereating and underrecording of habitual food intake in obese men: selective underreporting of fat intake. Am J Clin Nutr. 2000;71:130-134.

24. Westerterp KR, Goris AHC. Validity of the assessment of dietary intake: problems of misreporting. Curr Opin Clin Nutr Metab Care. 2002;5:489-493.

25. Johansson G, Wikman A, Ahren A-M, Hallmans G, Johansson I. Underreporting of energy intake in repeated 24-hour recalls related to gender, age, weight status, day of interview, educational level, reported food intake, smoking habits and area of living. Public Health Nutr. 2001;4:919-927.

26. Prentice AM, Black AE, Coward WA, Cole TJ. Energy expenditure in overweight and obese adults in affluent societies: an analysis of 319 doubly labeled water measurements. Eur J Clin Nutr. 1996;50:93-97.

27. Ekelund U, Aman J, Yngve A, Renman C, Westerterp K, Sjöström M. Physical activity but not energy expenditure is reduced in obese adolescents: a case-control study. Am J Clin Nutr. 2002;76:935-941.

28. Prentice AM, Jebb SA. Obesity in Britain: gluttony or sloth? $\mathrm{Br}$ Med J. 1995;311:437-439.

29. Goris AHC, Westerterp KR. Physical activity, fat intake and body fat. Physiol Behav. 2008;94:164-168.

30. Swinburn BA, Sacks G, Lo SK, et al. Estimating the changes in energy flux that characterise the rise in obesity prevalence. Am J Clin Nutr. 2009;89:1723-1728. 
31. Schoeller DA, Shay K, Kushner RF. How much physical activity is needed to minimize weight gain in previously obese women? Am J Clin Nutr. 1997;66:551-556.

32. Weinsier RL, Hunter GR, Desmond RA, Byrne NM, Zuckerman PA, Darnell BE. Free-living activity energy expenditure in women successful and unsuccessful at maintaining normal body weight. Am J Clin Nutr. 2002;75:499-504.

33. Westerterp KR. Alterations in energy balance with exercise. Am J Clin Nutr. 1998;68:S970-S974.

34. Forbes-Ewan CH, Morrisey BLL, Gregg GC, Waters DR. Use of doubly labeled water technique in soldiers training for jungle warfare. J Appl Physiol. 1989;67:14-18.

35. DeLany JP, Schoeller DA, Hoyt RW, Askew EW, Sharp MA. Field use in D2180 to measure energy expenditure of soldiers at different energy intakes. J Appl Physiol. 1989;67:19221929.

36. Hoyt RW, Jones TE, Stein TP, et al. Doubly labeled water measurements of human energy expenditure during strenuous exercise. J Appl Physiol. 1991;71:16-22.

37. Jones PJH, Jacobs I, Morris A, Ducharme MB. Adequacy of food rations in soldiers during an arctic exercise measured by doubly labeled water. J Appl Physiol. 1993;75:17901797.

38. Burnstein R, Epstein Y, Coward WA, et al. Energy balance in subjects performing physical efforts in cold climate. Med Sci Sports Exerc. 1993;25(Suppl 1):S43.
39. Haggarty P, McGaw BA. Energy expenditure of elite female runners measured by doubly-labelled water method. Proc Nutr Soc. 1988;47:74A.

40. Schulz LO, Alger S, Harper I, Wilmore JH, Ravussin E. Energy expenditure of elite female runners measured by respiratory chamber and doubly labeled water. J Appl Physiol. 1992;72:23-28.

41. Sjödin AM, Andersson AB, Högberg JM, Westerterp KR. Energy balance in cross country skiers. A study using doubly labelled water. Med Sci Sports Exerc. 1994;26:720-724.

42. Westerterp KR, Saris WHM, van Es M, ten Hoor F. Use of the doubly labeled water technique in humans during heavy sustained exercise. J Appl Physiol. 1986;61:2162-2167.

43. Westerterp KR, Saris WHM. Limits of energy turnover in relation to physical performance, achievement of energy balance on a daily basis. J Sports Sci. 1991;9:1-15.

44. Jackson DM, Djafarian K, Stewart J, Speakman JR. Increased television viewing is associated with elevated body fatness but not with lower total energy expenditure in children. Am J Clin Nutr. 2009;89:1031-1036.

45. Westerterp KR. Obesity and physical activity. Int J Obes. 1999;23:59-64.

46. Tanskanen M, Uusitalo AL, Häkkinen K, et al. Aerobic fitness, energy balance and body mass index are associated with training load assessed by activity energy expenditure. Scand J Med Sci Sports. 2009;19:871-878. 